\title{
Testing the input-process-output model of public participation
}

\author{
CAROL GALAIS, ${ }^{1}$ JOSÉ LUIS FERNÁNDEZ-MARTÍNEZ, ${ }^{2}$ JOAN FONT ${ }^{3}$ \\ \& GRAHAM SMITH ${ }^{4}$ \\ ${ }^{1}$ Political Science and Public Law department, Universitat Autònoma de Barcelona (UAB), Spain; ${ }^{2}$ Department of \\ Social Sciences, Universidad Carlos III de Madrid, Spain; ${ }^{3}$ CSIC-Instituto de Estudios Sociales Avanzados, \\ Consejo Superior de Investigaciones Cientificas, Spain; ${ }^{4}$ Centre for the Study of Democracy, University of \\ Westminster, UK
}

\begin{abstract}
The characteristics of participatory institutions can be articulated in three main dimensions: input, process and output. The common assumption is that a dependency relationship exists, with process serving as a mediator between input and output. This paper puts the model to a rare empirical test drawing on a unique dataset of 70 Spanish advisory councils. Through a combination of exploratory factor and path analyses, we analyse the dimensionality of input, process and output and investigate the direct and indirect impact of inputs on process and outputs. Our analysis provides evidence that input factors have a direct impact on the output factor transparency, but their impact on effects on policy and participant satisfaction is mediated by the process factor deliberation. Further, the capacity of the public administration to steer the advisory council (wardship) mediates negatively the impact of input variables on transparency. The analysis provides a nuanced account of how different input and process design characteristics of participatory institutions have profound direct and indirect effects on their outputs.
\end{abstract}

Keywords: advisory councils; associative democracy; participatory democracy; indirect effects; path analysis; inputs; outputs; process

\section{Introduction}

As the use of participatory institutions ${ }^{1}$ by public authorities has proliferated, so too has the literature on their assessment. Broadly, three dimensions have been the focus of analysis that can be characterised as 'input', 'process' and 'output' (Beierle \& Crayford 2002; Agger \& Löfgren, 2008; Burgess \& Chilvers 2006; Landwehr \& Holzinger 2010; Gastil et al. 2017; Pogrebinschi $\&$ Ryan 2018). Input refers to the conditions and context that shape the engagement process, for example, who participates, the intended task, resources used and so forth. Process refers to the internal dynamics and interactions between participants. Output refers to the effects or impact of participatory institutions in terms of policy formulation and implementation (Font et al. 2018) as well as impacts on the individual political efficacy and learning of participants (Talpin 2012).

The way these different characteristics are articulated and their relationship are very much influenced by the theoretical perspective employed. Yet, the output of a participatory institution is typically understood as the product of the influence of input and process variables, following a linear and path-dependency dynamic (Hoppe 2011) in which input factors exert an indirect effect on outputs through process characteristics. While this assumption of path dependency is widespread, it is rare to see the causal chain of the input-process-output (IPO) put to empirical test and the mediating role of process dynamics assessed. This paper is thus original in modelling the

[Correction added on 4 December 2020 after first online publication: Text corrections have been made for clarity on pages 2, 6-14, 18 and 19.] 
direct and indirect effects of inputs on outputs, in particular testing the extent to which they are mediated through process factors.

For this purpose, we draw on a Spanish dataset of a sample of 70 Advisory Councils (ACs). ACs are a 'traditional' participatory institution (Lowndes et al. 2001) that display the characteristics of associative democracy and collaborative governance in that they engage citizens and representatives of different social groups in dialogue with representatives of the public authority. In spite of being one of the most abundant forms of participatory institutions (Cooper \& Musso 1999; Coelho 2006; Sintomer \& de Maillard 2007; Fobé et al. 2013), the democratic qualities of ACs have seldom been addressed. In part this is because of the tendency in academic studies to focus on "innovative" democratic forms (for example, participatory budgeting and deliberative mini-publics), overlooking more mundane practices (Spada \& Ryan 2017; Smith 2019).

From the population of ACs in Spain, we draw on data at the national, regional and municipal level for four types of council: environment, education, immigration and territorial. We adopt a rigorous combination of methods, rarely used within studies of participatory institutions exploratory factor analysis and path analysis - to address the direct and indirect effects of input and process traits on the outcomes of ACs.

Several factors emerge from the exploration of the dimensionality of input, process and output. These dimensions are complex. Process in particular is multidimensional, capturing not only the aspects of voice and deliberation, but also the 'wardship' function of the public administration - its capacity to steer or control the participatory institution. Process dimensions contribute independently to AC outputs, which themselves can be separated into policy-related effects and transparency of outputs. Our analysis indicates that input variables exert both an indirect and a direct effect on outputs, that deliberation is the main mediator of the effects of inputs on policy effects and that attempts to steer ACs on the part of public administration act as a powerful suppressor of the impact of inputs and have a particularly dampening effect on the transparency of outputs.

\section{The IPO approach to the study of participatory institutions}

IPO models have been influential in political analysis, particularly in the analysis of the legitimacy of political systems (Scharpf 1999). While this schema is not always explicitly articulated in studies of participatory institutions, the variables that are chosen and the logic of the relationship between them can generally be captured in these terms. In his oft-quoted work, Fung regularly postulates the relationship between different input, process and output factors (without using those designations explicitly) in his analysis of different participatory institutions. His 'democracy cube' (Fung 2006), for example, combines elements of input (who participates) with aspects of process (mode of communication and decision-making powers). In an earlier piece, he considers such design characteristics alongside outputs such as individual transformations, social justice, efficacy of policies and popular mobilisation (Fung 2003). Similarly, Smith's (2009) account of democratic goods of inclusiveness, popular control, considered judgment and transparency mixes input, process and output factors.

Building on the work of Scharpf; Papadopoulos and Warin (2007) propose openness and access as the main indicators for "input legitimacy", the quality of democratic activity for "throughput legitimacy" and efficiency and effectiveness as "output-legitimacy" indicators. They add to their 
model publicity, transparency and accountability as a potential fourth dimension that other authors have labelled "outcomes" (Hoppe 2011). From an explicitly deliberative perspective, Felicetti et al. (2016) distinguish between inclusiveness, authenticity and consequentiality. The comparative framework developed by Hassenforder et al. (2015) synthesises elements from the context, the decision-making process and a third dimension they term outputs, outcomes and impacts. The work of Gastil and various colleagues has been particularly influential, drawing on the common use of the IPO framework in small group research (Pavitt 1999; Gastil et al. 2012). Gastil and colleagues have developed a schema designed to test the tenets of deliberative engagement, distinguishing between input (context and purpose of engagement, structural features and resources), process (democratic participants relations and analytic rigour of deliberation), and two types of output direct outcomes (decision satisfaction and decision quality) and indirect outcomes (participant transformation and policy/social outcomes). The schema is presented explicitly with process variables as mediators between input and output.

While much of this work has been focused on laying out the IPO dimensions conceptually, a number of empirical studies have begun to test relationships. The literature on environmental collaborative governance ${ }^{2}$, for instance, has generally paid attention to the relationship between inputs and outputs (Newig \& Fritsch 2009; Newig et al. 2018; Newig et al. 2019; Baldwin 2020) - in some cases considering what others would take to be process characteristics as inputs. Biddle and Koontz (2014), for example, use a path analysis to link collaborative processes to environmental outcomes through intermediate outputs. Within work on deliberative democracy, the focus has been very much on the implications of the design of process characteristics (Smith 2009; Felicetti et al. 2016; Grönlund et al. 2017), often overlooking inputs and, where they are considered, typically restricting the analysis of outputs to the impact of deliberation on preferences (and on occasion behaviours). Research on the effect of deliberation has made substantial methodological advances, for instance by combining large $\mathrm{n}$ databases, experimental evidence and complex statistical models to tackle the causal effects of deliberation on citizens' attitudes (Baccaro et al. 2016; Goldberg et al. 2020).

In a recent study, Participedia data are exploited to test the association of IPO dimensions in Gastil's model (Gastil et al. 2017). To our knowledge this is the nearest anyone has come to testing systematically a full IPO model, but it is limited in two respects. First, it only tests the associations between pairs of variables. It does not test, for example, the relative effect of the direct or indirect relationship between input and output variables compared with the effect of process variables. Hence the mediating role of the latter is not assessed. In this sense, Gastil's formulation assumes a path dependency in which input only affects process, which in turn affects output (Hoppe 2011). Second, the analytical framework has been generated with the explicit intention of evaluating the deliberative quality of participatory institutions. The articulation of input and process variables is drawn from deliberative democratic theory and from existing deliberative analytical frameworks. The influence of 'non-deliberative' or even 'anti-deliberative' factors - for example, the actions of public authorities to steer or control participatory processes - are not considered in the explanation of outputs.

\section{Defining IPO for advisory councils}

In this paper we put an IPO model to the test on a common form of participation, advisory councils. Our decision to focus on what is a relatively mundane participatory institution is driven by two 
interconnected reasons. First, the tendency to study 'democratic innovations' - new forms of public participation - is skewing our understanding of participatory institutions. By considering only the most vibrant and innovative forms of participation, we overlook the study of more established and common forms of engagement. Second, democratic innovations, by their nature, are rare and often isolated phenomena from which generalisations are difficult to draw (Spada \& Ryan 2017; Smith 2019). The prevalence of ACs means that data can be made available to undertake meaningful comparative analysis.

While diversity exists in how ACs are institutionalised, the term 'advisory councils' marks the collective nature of these settings, and their advisory relationship with public authorities. Our definition of ACs has three characteristics:

(1) a formal existence with explicit links to public administration;

(2) a permanent feature of the institutional environment;

(3) a degree of citizen involvement, typically through associational membership. ${ }^{3}$

As multistakeholder bodies that involve both civil society actors and public officials, advisory councils can be understood as a form of associative democracy (Cohen \& Rogers 1995). Associative democracy aims to bring together the variety of social interests, to solve functionally specific problems (Cohen 1997). Such arrangements are taken to increase the legitimacy of government by ensuring that all relevant interests are able to contribute to policy development (Held 1993). ACs are an abundant form of participatory institution, in Spain (Navarro 1999) as well as in a large variety of other European, American and Asian contexts (Cooper \& Musso 1999; Campos \& Gonzalez 1999; Coelho 2006; Sintomer \& de Maillard 2007; Fobé et al. 2013).

ACs can be both territorial and sectorial. Territorial ACs consider the policies in a specific geographical area (district or neighbourhood) (Sirianni 2007). Sectorial councils focus on specific policy fields or specific sectors of the population. In addition to government and civil society actors, ACs can also include experts or representatives of other public administrations. The number of participants representing each organization (or type of organization) is normally established by laws or local regulations. The participants are most frequently appointed by the leadership of each specific organization.

ACs always have a plenary (with usually 20 to 80 attendees) that meets a few times a year and sometimes have other more operational structures such as working commissions or an executive committee. Meetings involve provision of information and discussion on items that come from the public administration or from civil society members themselves. In terms of decision making, the practice of ACs varies, with some formally voting on issues, others using consensual processes, and others being more a place for information exchange rather than decision making.

ACs appeared in Spain in the 1980s. Over the following decades, they expanded in federal, regional and municipal administrations (Navarro 1999). Their policy focus extended from the first cases that were devoted to more traditional social and economic policies to cover diverse policy fields, including environment in the late 1990s (Jiménez 2001) and identity-based policies (from immigration to LGBT issues) in the following decade.

In articulating an IPO model, our aim is not to evaluate one particular normative theory. This distinguishes our approach from that adopted by Gastil et al. $(2012,2017)$ and Felicetti et al. (2016) who aim to evaluate the claims of deliberative democrats; to test the extent to which deliberative 
ideals are realised in participatory institutions. Much of the literature on participatory institutions and on IPO modelling is highly structured by the deliberative perspective. Our ambition is more ecumenical. We are interested in the effect of deliberative characteristics but do not assume that these are the only qualities relevant to participatory institutions (Smith 2019). In our approach to the relationship between input, process and output factors, deliberative practice is considered as only one element of participatory politics.

\section{Input}

In defining input, normative and practical factors are both relevant. The shared starting point for almost all IPO models is consideration of the representativeness of participants. For Rowe and Frewer (2000), for example, representativeness (that is, the extent to which participants comprise a broadly representative sample of the population of the affected public) is a critical legitimacy criteria of participatory institutions. They regard ACs as scoring moderately to low regarding representativeness of participants when compared to the use of random selection. Font (2003) and Romão et al. (2017) offer a contradictory perspective, considering ACs as a successful case in ensuring representativeness across all relevant social interests. Here the importance is that relevant social groups rather than a statistically representative sample are present. A number of studies of ACs address their capacity to incorporate traditionally excluded actors from a variety of social backgrounds (Wampler 2007; Edwards 2008; Hernández-Medina 2010; ), while others have raised concerns about participatory bias where particular interests are not present (Navarro 1999; Aguiar \& Navarro 2000). Where social groups are not present, decisions are unlikely to fully recognise their perspectives. The literature on collaborative governance warns us that the inclusion of all relevant stakeholders is crucial to guaranteeing the legitimacy of any participatory process (Ansell \& Gash 2008).

While representativeness is the most widely considered normative characteristic, too often critical practical factors are overlooked. The quickest way to undermine a participatory process is to starve it of the resources it needs to function (Baldwin 2020; Dean et al. 2019). Thomas and Koontz's (2011; see also Biddle \& Koontz 2014) operationalisation of inputs, based on human, financial and technical resources, is a reminder of such overlooked dimensions. Their research on environmental outcomes draws attention to another relevant explanatory factor: the specificity of policy goals in the commissioning and implementation of participatory institutions. In the same vein, Bherer et al. (2016) highlight the importance of establishing and communicating clear goals before taking participatory actions. We can expect these more practical input dimensions to have differential effects, with resources directly affecting process characteristics and thus having an impact on outputs; while an explicit policy orientation may well have a direct effect on outputs such as impact on policy.

In our analysis of input, we thus attend to the combination of the representativeness of participants, availability of resources and specificity of goals.

\section{Process}

Aspects of deliberative quality have captured the imagination of many scholars and activists: ACs and other participatory instruments are very often judged by the extent to which they enable deliberative forms of interaction. We find differences in research strategy to assessing 
deliberative quality. Some authors bring standards of, for example, justification rationality to bear (Baccaro et al. 2016), often on transcripts of participatory processes. Other studies rely on subjective measures provided by participants (Morciano et al. 2014) or on assessments of the quality of information provided to participants (Font \& Galais 2011; Gastil 2013). Gastil (2008) offers an account of the multidimensionality of deliberation, identifying two sub-dimensions: the analytic rigor of the deliberative process and the quality of social interactions, including respect, consideration and equality of opportunity (2008: 2). Following Gastil, our analysis combines consideration of the quality of information available to participants and the form of social exchange that takes place within the participatory process (Gastil 2013).

Voice is often considered an aspect of deliberation: deliberation presupposes that participants are willing and able to make their voice heard, both in interactions and in any decisionmaking method employed (Young 1990; Phillips 1993; Smith 2009). But voice can be distinguished analytically from deliberation. Participatory institutions can provide the opportunity for participants to voice their perspectives irrespective of whether interactions are deliberative in character. At the same time decision making rules have implications for voice, not only in terms of their clarity and predictability (Diamond \& Morlino 2005), but also in the way that interests are aggregated. Decision making can vary from procedures that enable veto powers to be exercised, to simple, qualified or absolute majorities, through to assent procedures where verbal support for proposals is offered in plenary. Different decision rules can have profound impacts on the capacity to voice dissent. Feminists have long argued that consensus procedures can enable the exercise of power by the most powerful, with traditionally marginalised groups unwilling to make their concerns public (Fraser 1990; Young 1990). Research on the gender composition of participatory spaces suggests that this may not always be the case, with rules requiring unanimity enabling women in a minority to veto decisions (Karpowitz \& Mendelberg 2014).

The focus on promoting voice and deliberation needs to be tempered. Our knowledge of participatory processes is that they can easily become tools dominated by the administration (Newman et al. 2004: 211-12; Hoppe 2011). For example, work on the extent of implementation of proposals from participatory institutions shows that administrations 'cherry-pick' those that fit with existing political commitments (Font et al. 2018). In ACs, in particular, the presence of public officials within the participatory space increases the potential that they will dominate proceedings, steering the agenda and decision making. The danger is that ACs become tools of the bureaucracy or co-opted spaces.

Thus, in attending to process, we need to be aware of the extent to which voice is realised for participants and the extent to which ACs embody deliberative and co-optive dynamics.

\section{Output}

A wide array of typologies of the impacts of participatory institutions exist that vary in terms of their timing (short vs long term effects), type of impact (social, political, etc.) and the nature of such impacts (tangible or intangible) (see Hassenforder et al. 2015; Baldwin 2020). Gastil et al. (2012), for instance, distinguish between direct outcomes (the quality of decisions or recommendations and the impact on public policies) and indirect outcomes (participants' attitudes and broader impact 


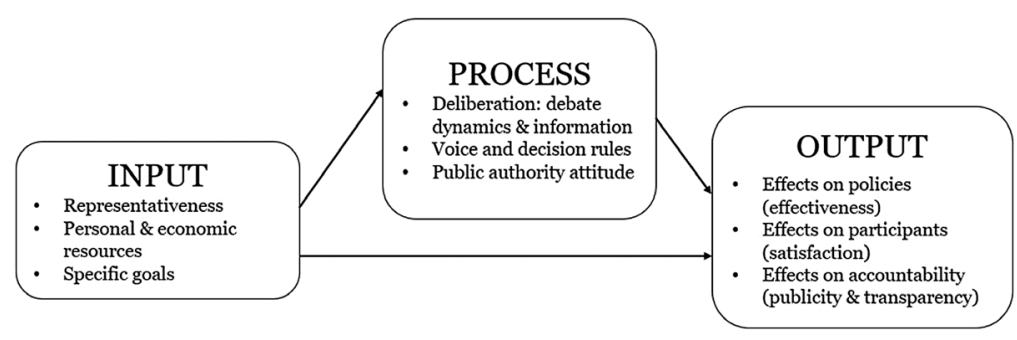

Figure 1. IPO main elements and direct and indirect effects to be tested.

on civil society). Clear distinctions emerge between studies interested in the impact on political decision making (e.g., Innes \& Booher 1999; Webler \& Tuler 2002) and those more interested by the effect on participants (e.g., Carr \& Halvorsen 2001; Daniell 2012).

While impacts on either (or both) policy and participants are standard considerations amongst analysts of participatory processes, practical actions taken to publicise the activities and decisions of ACs are rarely featured. Publicity and transparency are critical for broader accountability (Bherer et al. 2016). Recent studies have highlighted the deficit of publicity when trying to discover the recommendations from participatory institutions, such as publicly accessible reports, recommendations, minutes or lists of selected proposals (Font et al. 2016: 8). As Hoppe (2011) stresses, dissemination is one of the main outputs of a participatory process: poor dissemination compromises accountability to the public. In principle the more extensive use of information and communications technologies (ICTs) should improve publicity and transparency of participatory institutions. The extent to which this is the case has not been the subject of analysis.

Our analysis of outputs thus needs to capture standard concerns related to policy effects and impacts on participants, but also the extent and form of dissemination.

\section{Summary}

Factors that explain the democratic qualities of ACs can be articulated in relation to input, process and output. The temptation is to assume input and output are mediated by process - a simple path dependency exists between the three factors. But such path dependency should not be assumed as it is too often in research on environmental collaborative governance and deliberative democracy. A mediation effect requires us to explicitly estimate the effects of inputs on outputs, while also taking into account the potential internal complexity of these factors. It is possible that a direct causal relationship coexists with an indirect one, meaning that some input traits have an effect on outputs regardless of process characteristics. The consideration of both direct and indirect effects simultaneously taking into account the dimensionality of the three IPO factors is an original and significant contribution to the literature, along with our attention to a long-disregarded participatory mechanism - ACs. Figure 1 summarises the basic model to be tested, as well as the main elements to be considered within each of the three IPO factors (note that some of them might be tapped using more than one indicator). 


\section{Research design}

\section{Data and sampling strategy}

Our dataset incorporates information on 70 Spanish ACs. The first stage in developing the dataset was a mapping of the existing ACs at national and regional (17 regions) levels and within municipalities with more than 250,000 inhabitants (or more than 175,000 if the capital of their province is excluded, 25 municipalities in total). A web search strategy examined the available information across all departments within each public administration. In those cases where information on ACs did not exist or was too limited to be credible, we made a direct phone request to the administrations concerned. The dual search strategy yielded information for a total of 2,013 ACs, which are present in almost every policy field, with the largest presence in the economy (388) and the environment (283). Sectorial policy councils comprise the large majority of cases (85 per cent), with territorial councils (15 per cent) operating across a defined geographical area.

The second step was to select a manageable sample of ACs for further data collection, balancing the realisation of a diversity of cases in each policy area with the need to ensure a degree of comparability and a minimum number of cases in each of them. To this end, we selected four types of councils: one traditional social policy (education), one new policy (environment), and one identity policy (immigration), plus territorial councils (e.g., city centre districts). This selection should not be considered a fully representative sample of all existing ACs, but rather a diverse sample that includes a representation of different types of AC, both in terms of policy focus and territory. ${ }^{4}$

In the final sampling stage, we ensured all territorial levels were represented by selecting all cases at state and regional levels and one municipality (randomly selected) from each region. The result is a sample of 101 cases with the following distribution: 31 school councils (most of the public administrations had one), 28 environmental councils, 19 immigration councils (a more limited adoption by municipalities) and 23 territorial councils (almost all cities had one).

For each of these 101 cases we undertook two additional data collection strategies. First, we mined the web for the constitutional documents and functional rules for each AC. The information collected included mission and aims, composition, organizational structure and transparency. The coding of the institutional characteristics of these ACs was developed by three coders, using a common codebook and holding several meetings to discuss any difficult cases. This took place during spring 2017. Second, we launched an online survey of AC members to capture additional information that did not appear on web pages, including the subjective experience and perspective of participants. ${ }^{5}$

The survey was fielded from November 2017 to March 2018 and targeted at all AC participants with a seat on the Council, whether citizens, organised stakeholders or public officials. We contacted the administration in charge of the AC, suggesting two ways to distribute the questionnaire: either they provided the email addresses of participants (used for $27 \mathrm{ACs}$, with a response rate of 30.3 per cent) or the administration itself sent a link to the online questionnaire to each member of the council (43 ACs, with a 12.5 per cent response rate). The response rates did not vary dramatically among types of councils, with educational councils the largest at 23.5 per cent and territorial councils the lowest at 11.5 per cent $^{6}$. For 31 ACs it was impossible to reach the participants. This group includes ACs that exist only formally but with no practical activity, and others that refused to cooperate or which could not be contacted after several attempts. In 
total 569 individuals responded from 70 ACs. Politicians made up 13.5 per cent of the final respondents and 15.3 per cent were public servants. The rest (71 per cent) were citizens, with 14 per cent representing trade unions, 9.3 per cent representing business organizations, and 8 per cent 'experts' in the relevant policy field. The most frequent profile of respondents (36.6 per cent of the total) were individuals representing associations, Non-Governmental Organisations or federations of associations. ${ }^{7}$ This is the only group whose representation in our sample deviated significantly from what we expected given the formal rules of the ACs which suggested that organised interests comprised 27.7 per cent of participants. Other categories displayed differences no higher than 5 per cent.

Our final dataset therefore consisted of 70 ACs at national $(n=5)$, regional $(n=35)$ and municipal $(\mathrm{n}=30)$ levels, for which both subjective and objective information was available. The "objective" information relied on online content and independent coders. The "subjective" information was provided by AC participants. The first data source was prioritised to reduce measurement error, although the second was critical to tap subjective phenomena (e.g., participants' satisfaction) and to fill in information (e.g., how often voting is used in practice) that the public documentation did not address. ${ }^{8}$

\section{Variables}

The aim of the data collection strategy was to tap variables across input, process and output factors. Not all relevant elements could be captured, but the variables generated represent, arguably, the most extensive attempt to capture systematically input, process and output variables. ${ }^{9}$ Whenever survey responses could be ranked (numerical and ordinal variables), they have been averaged, assigning to each case (council) the mean value or percentage (for dichotomous questions) of the responses.

\section{Input measures.}

Representativeness. Given the lack of 'objective' information from documentation, we drew on AC attendees' perceptions of the diversity of the council. More precisely, we used two agree/disagree seven-rung scale $(1=$ strongly disagree and $7=$ strongly agree $)$ variables, tapping whether participants considered the composition of the plenary politically diverse and whether all important stakeholders were represented. Higher values indicate more diversity in both cases.

Goal and purpose. From AC documentation, we discerned whether the council has 'public policies' among its declared objectives $(0=$ no and $1=$ yes $)$. Our assumption is that such a statement indicated an expectation that the AC has policy effect - and that this affects the behaviour of participants during the process.

Resources. An additive scale was employed that captured whether the council had its own staff $(0=$ no and $1=$ yes $)$ and budget $(0=$ no and $1=$ yes $)$. The resulting scale ranges from zero (no resources) to two (both own staff and budget).

\section{Process measures.}

Voice. Four variables captured different aspects of voice taken from the official documentation (all defined as $0=$ no and $1=$ yes). First, whether attendees were given a formal right to voice 
their opinion. Second, whether they were given the right to vote. Third, the presence of simple majority voting was included as a dichotomous variable, the alternatives being qualified or absolute majority. Fourth, from the survey, we created a dichotomous variable that indicates whether assent is commonly used as a decision-making method.

Deliberation. Three variables were used, one capturing information, the other two capturing interactions. To capture perceptions about the level of information provided, a subjective satisfaction scale was employed consisting of three agree/disagree questions (from strongly disagree $=1$, to strongly agree $=7$ and Cronbach's alpha $=0.92$ ). These questions asked whether the information received was enough to make good decisions, whether such information was diverse and unbiased and whether it was provided when asked for. Two agree/disagree questions $(1=$ strongly disagree and $7=$ strongly agree $)$ tapped the dynamics and quality of the interactions between participants: how constructive debates were and to what extent those debates were well structured.

Dominance of public administration. Where both president and vice-president of the AC were members of the public administration and not elected to these positions, this was captured by the value 1,0 if otherwise.

\section{Output measures.}

Policy results. A variable built from three questions captured the perceived quality of advice provided by the AC: whether participants thought recommendations represent the diversity of perspectives in the council, whether the recommendations were clear and whether they had broad social support. The addition of these three items yielded a scale ranging from 0 (no quality traits) to 3 (the three quality traits are present, Cronbach's alpha $=0.87$ ).

Participant satisfaction. The values of six different indicators related to the production of policy recommendations were added in a single scale. The six questions tapped whether participants were satisfied with the point in time at which the request for advice arrived, the time they had to produce the advice, the scope of the debates, their personal contribution being taken into account, the overall quality of advice and whether the final advice by the AC was taken into consideration by the administration (Cronbach's alpha $=0.87) .{ }^{10}$

Transparency of AC products. We considered whether the AC's reports and recommendations were made available online, whether the $\mathrm{AC}$ website was kept updated and whether the $\mathrm{AC}$ had a social networking presence $(0=$ no and $1=$ yes, in all cases $)$.

\section{Methods}

The analysis followed a two-step process: a series of exploratory factor analyses (EFA) and a path analysis to test the mediating role of process in the IPO model. We resort to EFA to reduce the number of variables involved in the analyses. While previous research suggests relationships between the input, process and output factors, we were open to uncovering different patterns. After rescaling the values of all non-dichotomous variables to be in the range $0-1$, we first estimated the three factors (input, process and output) separately, applying principal components and varimax 
Table 1. Factor analysis for the 'input' indicators. Principal component analysis

\begin{tabular}{lcc}
\hline Variable & Factor loading & Uniqueness \\
\hline Resources & 0.82 & 0.33 \\
Declared objective values: public policies & 0.80 & 0.35 \\
Perceptions on composition: diversity $^{\mathrm{a}}$ & 0.56 & 0.68 \\
Perceptions on composition: all important stakeholders are present $^{\mathrm{a}}$ & 0.60 & 0.64 \\
\hline
\end{tabular}

${ }^{\mathrm{a}}$ The variable was measured using the surveys to participants, responses averaged by AC.

rotation which produced orthogonal (i.e., independent) factors minimizing multicollinearity problems in subsequent analysis. ${ }^{11}$ The resulting factors were used to estimate a path analysis which put the indirect and direct effects presented in Figure 1 to empirical test. Path analysis is a special case of structural equation models that does not deal with measurement error, hence presenting only structural (path) coefficients. ${ }^{12}$ This estimation considered 'output' the ultimate dependent variable, but process dimension(s) were also considered simultaneously as dependent variable(s) impacted by inputs. The effects of inputs were modelled as a combination of direct and indirect effects on the outputs, partly or totally mediated by the process factors.

\section{Results}

\section{Measuring input, process and output}

Table 1 depicts the results for an EFA testing whether our four 'input' measures load on the same underlying construct. The results confirmed that this is the case. The resulting factor (mean $=0$ and $\mathrm{SD}=1$ ) was saved, to be used in the estimation of the IPO model.

Table 2 provides the results of the same analysis for the process indicators. The results show that process was not a monolithic construct, but rather contained at least three sub-dimensions within it. The first we labelled 'deliberation' which includes satisfaction with the information given to participants, and opinions on the constructive character of interactions and the structure of the debate. The second factor captured aspects of 'voice', including the opportunity to voice opinions and to vote and includes majority voting. Finally, we find that two variables loaded together to indicate the potential for dominance by the public administration: the use of assent as a common method for decision-making and public officials in the position of president and vice-president of the AC.

Table 3 performs the test on output indicators. In this case, the eight indicators loaded in two different dimensions which can be interpreted as the effects (impacts on policy, quality of advice, satisfaction with AC's performance, production of advice) and the transparency of such outputs.

\section{Testing the IPO model}

In the next step, we estimated the two resulting output factors by means of a path analysis that considered the other four factors (three for the process, one for the input) as explanatory factors. The final model put to empirical test is presented in Figure 2, which considered the direct and indirect effects. The results of the estimation are displayed in Table 4 and Figure 3. 
Table 2. Factor analysis for the 'process' indicators. Principal component analysis. Varimax rotated results

\begin{tabular}{|c|c|c|c|c|}
\hline Variable & $\begin{array}{l}\text { Factor } 1 \text { loading } \\
\text { Deliberation }\end{array}$ & $\begin{array}{c}\text { Factor } 2 \\
\text { loadingVoice }\end{array}$ & $\begin{array}{l}\text { Factor } 3 \text { loading } \\
\text { Wardship }\end{array}$ & Uniqueness \\
\hline Members voice their opinions & & 0.93 & & 0.14 \\
\hline Members vote & & 0.93 & & 0.13 \\
\hline $\begin{array}{l}\text { Decision making rules: simple } \\
\text { majority }\end{array}$ & & 0.78 & & 0.35 \\
\hline $\begin{array}{l}\text { Satisfaction with information } \\
(\text { scale })^{\mathrm{a}}\end{array}$ & 0.88 & & & 0.22 \\
\hline $\begin{array}{l}\text { Agree with: the interaction within } \\
\text { the members of the plenary } \\
\text { proceeds constructively }\end{array}$ & 0.88 & & & 0.22 \\
\hline $\begin{array}{l}\text { Agree with: the debate is well } \\
\text { structured }^{\text {a }}\end{array}$ & 0.87 & & & 0.20 \\
\hline $\begin{array}{l}\text { Decision making methods: assent, } \\
\text { routinely }^{\mathrm{a}}\end{array}$ & & & 0.85 & 0.23 \\
\hline $\begin{array}{l}\text { The president \& vice-president } \\
\text { represent the public } \\
\text { administration }\end{array}$ & & & 0.79 & 0.28 \\
\hline
\end{tabular}

${ }^{\mathrm{a}}$ The variable was measured using the surveys to participants, responses averaged by AC. Only factor loadings higher than 0.5 are shown.

Table 3. Factor analysis for the 'output' indicators. Principal component analysis. Varimax rotated results

\begin{tabular}{lccc}
\hline Variable & $\begin{array}{c}\text { Factor 1 loading } \\
\text { Effects }\end{array}$ & $\begin{array}{c}\text { Factor 2 loading } \\
\text { Transparency }\end{array}$ & Uniqueness \\
\hline $\begin{array}{l}\text { The council has a social } \\
\text { networking site profile }\end{array}$ & & 0.72 & 0.48 \\
$\begin{array}{c}\text { AC reports and recommendations } \\
\text { available online } \\
\text { Website is kept updated }\end{array}$ & 0.80 & 0.79 & 0.37 \\
$\begin{array}{c}\text { AC effects: the content of the } \\
\text { policy changes }\end{array}$ & 0.85 & 0.78 & 0.39 \\
$\begin{array}{c}\text { Quality of advice assessment. } \\
\quad \text { Subjective scale }\end{array}$ & 0.92 & & 0.35 \\
$\begin{array}{c}\text { Satisfaction with the performance } \\
\text { of the council. Subjective scale }\end{array}$ & & & 0.27 \\
\hline
\end{tabular}

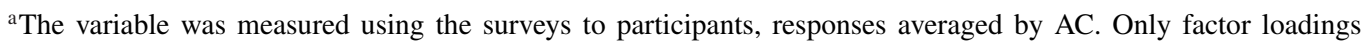
higher than 0.5 are shown.

The input factor explained between 2 and 24 per cent of the variation of the different process factors. In turn, input and process factors managed to explain 37 and 56 per cent of the variation of the output factors - being particularly successful in predicting the Effects sub-dimension. The overall goodness of fit $\left(\mathrm{R}^{2}\right)$ indicated that we have succeeded in explaining 44 per cent of the phenomena under study (considering the five dependent variables: the two output dimensions and the three process dimensions). 


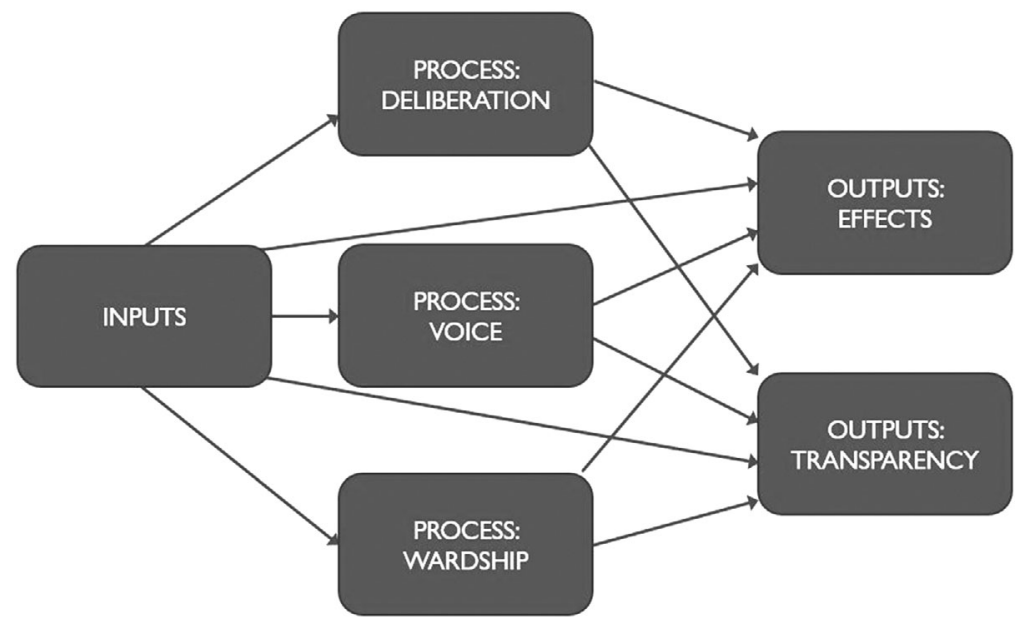

Figure 2. Final direct and indirect effects model to be estimated.

Table 4. Structural equation estimation of the effects of Inputs and Process. Standardised coefficients

\begin{tabular}{|c|c|c|c|c|c|}
\hline & $\begin{array}{c}\text { Process F1 } \\
\text { Deliberation } \\
\text { b/SE }\end{array}$ & $\begin{array}{c}\text { Process F2 } \\
\text { Voice } \\
\text { b/SE }\end{array}$ & $\begin{array}{c}\text { Process F3 } \\
\text { Wardship } \\
\text { b/SE }\end{array}$ & $\begin{array}{l}\text { Output F1 } \\
\text { Effects } \\
\text { b/SE }\end{array}$ & $\begin{array}{c}\text { Output F2 } \\
\text { Transparency } \\
\text { b/SE }\end{array}$ \\
\hline \multirow[t]{2}{*}{ Inputs } & $0.486^{* *}$ & 0.117 & $-0.408^{* *}$ & 0.03 & $0.39^{* *}$ \\
\hline & $(0.9)$ & $(0.12)$ & $(0.11)$ & $(0.10)$ & $(0.12)$ \\
\hline \multirow[t]{2}{*}{ Process F1 'deliberation' } & & & & $0.750^{* *}$ & -0.03 \\
\hline & & & & $(0.07)$ & $(0.11)$ \\
\hline \multirow[t]{2}{*}{ Process F2 'voice' } & & & & 0.046 & 0.176 \\
\hline & & & & $(0.08)$ & $(0.10)$ \\
\hline \multirow[t]{2}{*}{ Process F3 'Wardship' } & & & & 0.033 & $-0.291^{*}$ \\
\hline & & & & $(0.09)$ & $(0.11)$ \\
\hline \multirow[t]{2}{*}{ Constant } & 0.000 & 0.000 & 0.000 & 0.000 & 0.000 \\
\hline & $(0.10)$ & $(0.12)$ & $(0.11)$ & $(0.08)$ & $(0.09)$ \\
\hline $\mathrm{R}^{2}(\%)$ & $24 \%$ & $2 \%$ & $17 \%$ & $56 \%$ & $37 \%$ \\
\hline $\mathrm{R}^{2}$ overall (\%) & & & $44 \%$ & & \\
\hline
\end{tabular}

Note: Standard errors in parentheses. $*$ p-value $<0.01, * *$ p-value $<0.001$. Each column represents a different linear estimation for a different dependent variable: all the estimations are simultaneous. Estimations performed using the sem STATA command. $\mathrm{N}=70$.

The results are summarised in Figure 3. The input factor had a direct, positive impact on Deliberation and a negative one on Wardship. Input factors had no direct impact on Voice or Effects, but a sizeable positive one on Transparency.

Only two process factors contributed to outputs. Deliberation had a positive impact on Effects, but not on Transparency. Meanwhile, Transparency was seriously hampered by Wardship. The influence of Deliberation on Effects was more than twice as large as the one of Wardship on Transparency. 


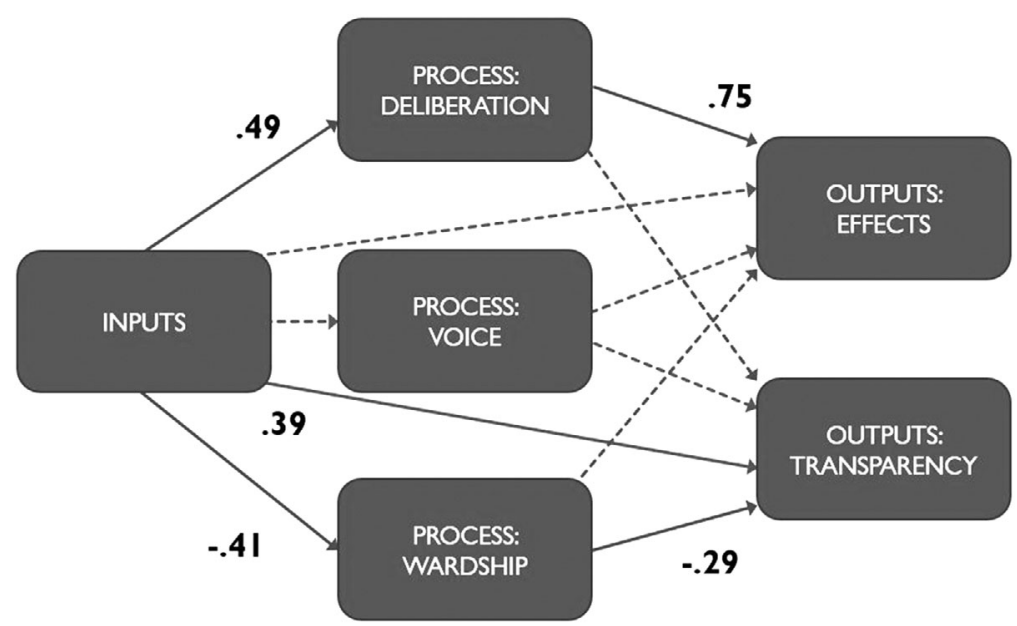

Figure 3. Direct and direct effects of input and process on output measures. Standardised coefficients.

Note: Dotted lines represent non-significant coefficients (paths). All shown coefficients are significant at $\mathrm{p}$-value $<$ 0.01. All paths have been estimated, but non-significant coefficients are not reported.

After calculating the total direct and indirect effects for all the exogenous variables (not shown), we can conclude that the input factor had a total impact on the Effects output factor equal to 0.39 , and an indirect effect of 0.36 . Almost all of the effect was indirect, mostly mediated by Deliberation. The process dimension had a noticeable mediation effect here. The input factor had a total effect on the second output factor, Transparency, equal to 0.52 . From this, 0.13 (hence 25 per cent) was mediated by Wardship. With its negative effect on Transparency (see last column in Table 4), Wardship emerged as a powerful suppressor of the positive effects of inputs on this output dimension.

\section{Discussion}

The power of IPO modelling is the promise that it will provide insights into the way in which different aspects of the design and practice of participatory institutions matter for their effects on policy, attitudes and the transparency of activities. Our analysis indicates that this is the case. Through factor analysis and path analysis we have a strong indication of the way in which input and process can affect outputs.

If we work backwards, from outputs, interesting findings emerge. The first relates to the variables that load together on the single factor Effects: policy effects, quality of advice and satisfaction of participants. These a priori distinct characteristics appearing as part of the same output dimension is a powerful signal that, even if analytically distinct, in practice they tend to strongly relate to each other. This result is in line with the findings of Gastil et al. (2017) that link the quality of decision to satisfaction of the participants, although in our setting these variables are not causally related, but part of the same underlying dimension.

Equally powerful is the evidence on the causal relationships that produce these outputs. First, the significant effect of inputs on deliberation, which then has a significant impact on these policy effects is a result that confirms previous research (Innes \& Booher 1999; Gastil et al. 2017). It is 
the combination of more representative, well-resourced and policy focused participatory processes that generates more deliberative process. And deliberation then has a significant impact on effects. Good design ensures good process that in turn leads to positive outputs. Sound institutional design, an authority that enables the process through investing resources, diversity in membership and focus on policymaking positively influences the dynamics and productivity of the debate within the AC, and this positively affects participants' satisfaction and perceptions about the AC's activity and influence.

The second dimension of outputs captures the transparency and publicity of the activities and recommendations of these institutions. While the importance of transparency had been claimed in previous research (Hoppe 2011; Bherer et al. 2016), empirical evidence is lacking that connects the achievement of transparency with input and process characteristics of participatory designs. Our findings indicate both encouraging and troubling reflections from a democratic perspective. The quality of input factors has a positive significant impact on transparency. A well-structured and funded participatory institution is likely to lead to publicity, with the encompassing potential effects on the wider public. But our results show that this positive effect can be seriously undermined by the mediating role of wardship on the part of the administration. Where the administration is able to unduly influence through positions of authority on the $\mathrm{AC}$ and the use of assent in decision making, this suppresses publicity. This effect is as important an explanatory factor as poor funding and vague orientation. Authorities that have too much influence on the activities of an AC are those that are least interested in explaining the how and why of AC outputs, possibly concerned that their instrumental use of participatory institutions will be made visible.

These results resonate with criticisms of participatory institutions as instruments for social control by public administrations (Hoppe 2011) and with recent findings that politicians and public officers 'cherry-pick' those outputs from participatory processes that are aligned with their preferences and interests (Font et al. 2018). Our results suggest that too often administrations steer these more traditional, associative participatory institutions to their own ends. Nevertheless, our results also indicate that inputs can limit the reach of public administrations. In other words, the better organised, funded and policy-oriented the AC, the less likely it is for politicians and public officers to steer the process.

While no direct impact is found between inputs and effects, this is not the case for transparency, where inputs have a positive and direct impact. A feasible explanation for this direct effect is that the early stages of the design of a participatory process are crucial for building commitment to the process by public authorities. Once a well-crafted participatory institution is in place, the interest of the respective public administration will be to communicate its results as widely as possible. In comparison, the satisfaction with the performance and decisions made by an AC depend to a greater extent on how the process develops. A too dominant role for the authority in the workings of the AC undermines the positive role of inputs (resources, clarity of rules, orientation towards public policies) in delivering transparency. Where an AC is diverse, well-resourced and has a clear policy task, most of the time we can expect it to be transparent in its outcomes. The input characteristics indicate that the public authority is taking the process seriously. Broader effects (particularly on subjective perceptions of participants) largely depend on how the process develops, particularly related to deliberation: the subjective experience of personal interactions is crucial to build satisfaction among the participants.

Finally, that voice is not a significant mediator for impact on effects or transparency is an intriguing finding, given the emphasis placed on this characteristic of participatory institutions. In 
our analysis, voice combines the capacity of participants to contribute to discussions and the use of simple majority voting as a decision-making method. But it is neither a consequence of inputs nor a cause for the ultimate outputs of the AC. To fully understand the impact of voice, we arguably need to know more about the internal composition of the AC - for example, gender dynamics. Only then can we unpack the relationship between, for example, gender composition and the effects of different decision rules (Karpowitz \& Mendelberg 2014). ${ }^{13}$

\section{Conclusions}

Our goal in this research was to put to empirical test the tripartite model of IPO that has an implicit and at times explicit hold on our understanding of participatory politics. Research on deliberation and mini-publics, on the one hand, and collaborative governance and environmental policies, on the other, include examples of empirical testing of causal mechanisms analogous to elements of the IPO chain. However, work on deliberation tends to focus mostly on the characteristics of the process, with some focus on the impact of preferences of participants; and studies of environmental governance, while typically more complex methodologically, tend to pay attention only to the relationship between inputs and outputs, at times considering process traits as inputs.

Through the development and analysis of a unique Spanish dataset that includes both objective and subjective information on a diverse set of 70 Advisory Councils, we take the analysis of IPO a step forward by estimating three different EFA models and undertaking a path analysis that simultaneously considers processes and outputs as dependent variables and assesses the mediating role of processes.

The results of our factorial analyses indicate that while input is a reasonably monolithic factor, process breaks down into three sub-divisions that capture elements of voice, deliberation and wardship. Output, in turn, can be differentiated between the perceptions of the effects of ACs and the transparency of their outputs.

What about the relationship between these factors? Is it simple path dependency from input to process to output as assumed in much of the literature? Our results suggest otherwise. Input has both direct and indirect effects. Its impact on effects is almost totally mediated by deliberation. In relation to transparency, inputs have a direct effect and an effect mediated by wardship. The key findings then are twofold. The first gives succour to deliberative democrats: well-designed processes tend to support deliberation which in turn leads to positive effects. The second finding is less positive from a democratic perspective: dominance by the administration suppresses transparency. Well-structured designs lessen this dominance. The IPO model provides important insights into the relationship between key variables, one that offers a more nuanced account of when and how aspects of design, deliberation and the exercise of power by public authorities can have significant impact on the outcomes of participatory democracy.

We must acknowledge limitations of our study, such as lack of information regarding the composition of ACs, exact budget and the clarity of internal rules. We also need to recognise our reliance on subjective measures provided by a non-probabilistic sample of AC participants. This led to missing data where respondents were unable to provide information on some variables not used in our analyses. The relatively small number of observations meant that the data were unfit for testing a measurement model for the IPO dimensions along with the structural paths.

While acknowledging limitations, the data and methods used to reach our results have clear advantages. The combination of objective and subjective data to build the dataset and the 
combination of factor analysis and path analysis represent a significant innovation. The cases examined also represent a comparable set of institutions based in a single cultural and political context. But how will the results stand up in a more diverse setting of policy areas, institutions and contexts? Given that ACs have been around for at least 40 years in Spanish and other contexts, and that 53 per cent of the ACs in our sample have existed for over two decades, we can assume that normative isomorphism has led to the spread of standard practice and convergence across cases. Spain is not exceptional in its democratic experience, territorial organization and political institutions. As such, our results are likely to be generalisable to other associationbased participatory institutions in advanced industrial democracies. But these assumptions need to be put to the test by selecting alternative policy areas and comparing across countries and other participatory institutions. Only then can we confirm the extent to which the traits we have discovered for Spanish ACs are replicated. What is clear, however, is that the IPO model deserves further attention within the study of participatory institutions.

\section{Acknowledgements}

We would like to thank the rest of the members of the ASSODEM (Associative Democracy: responsible autonomy, participatory bias or vicious circle) research project. The ASSODEM research project has benefited from a grant of the Spanish Ministry of Science and Innovation (CSO2015-66026-R).

\section{Appendix I: Descriptive statistics of the indicators employed in our analyses (Tables 1-3) after normalization}

\begin{tabular}{lllll}
\hline & Mean & SD & Min & Max \\
\hline Resources & 0.371 & 0.431 & 0 & 1 \\
Perceptions of council's diversity (s) & 0.715 & 0.156 & 0 & 1 \\
Declared objective values: public policies & 0.386 & 0.490 & 0 & 1 \\
Members voice their opinions & 0.886 & 0.320 & 0 & 1 \\
Members vote & 0.886 & 0.320 & 0 & 1 \\
Decision making rules: simple majority & 0.729 & 0.448 & 0 & 1 \\
Satisfaction with information (scale) (s) & 0.568 & 0.230 & 0 & 1 \\
Decision making methods: assent, routinely (s) & 0.229 & 0.423 & 0 & 1 \\
Agree with: the interaction within the members of the plenary & 0.646 & 0.189 & 0 & 1 \\
proceeds constructively (s) & & & & \\
Agree with: the debate is well structured (s) & 0.723 & 0.180 & 0 & 1 \\
The president \& vice-president represent the public adm. & 0.314 & 0.468 & 0 & 1 \\
The council has a social networking site profile & 0.114 & 0.320 & 0 & 1 \\
AC reports and recommendations available online & 0.514 & 0.503 & 0 & 1 \\
AC effects: the content of the policy changes (s) & 0.381 & 0.190 & 0 & 1 \\
Quality of advice assessment. Subjective scale (s) & 0.630 & 0.205 & 0 & 1 \\
\hline
\end{tabular}




\begin{tabular}{lcccc}
\hline & Mean & SD & Min & Max \\
\hline Satisfaction with the performance of the council (s) & 0.531 & 0.201 & 0 & 1 \\
The council website is kept updated & 0.557 & 0.500 & 0 & 1 \\
\hline
\end{tabular}

Note: (s) Indicates that the variable was measured using the surveys to participants, responses averaged by AC. The missing value for the variable "Satisfaction with the performance of the council" was imputed using variables measured at the municipal level.

\section{Notes}

1. Throughout the article, we use the terms participatory institutions and participatory processes interchangeably.

2. The way in which the term collaborative governance is used in the study of environmental governance would include participatory institutions such as ACs. Collaborative governance is defined by Baldwin (2020: 366) 'as any process that convenes diverse stakeholders outside of or in addition to the traditional regulatory process to share information, deliberate, and produce a set of recommendations that are used as an input to administrative decisions'.

3. ACs in Spain can be distinguished from those that are only or primarily constituted by independent experts (e.g., national regulatory agencies for energy) or from ad hoc advisory committees appointed by governments for specific issues.

4. The most significant policy area left out of our sample was the economy, which itself is highly diverse including many sector-specific councils (e.g., wine, clothing industry, etc).

5. The questionnaire is based on Fobé et al (2013). It includes questions tapping satisfaction with different parts of the participatory process, as well as a few questions asking about the usual functioning of the AC. More details about the administration of the survey can be found in Font et al (2019). We direct the reader to https://associativedemocracy.wordpress.com/ for more information about the project, the research design and the content and structure of the survey.

6. Territorial councils often include individual members and a much larger number of less committed participants, which could explain this lower response rate.

7. Alternative estimations of our models have been run excluding politicians and public officers from calculations and the results do not vary substantially.

8. If not explicitly specified, the measures presented below come from the 'objective' dataset relying on public documents.

9. Alternative measures were considered but discarded if the number of missing values exceeded one. See Appendix I for a more detailed description of the indicators employed in our analyses.

10. This scale is the only indicator for which we lack information for one AC. We decided to impute its value predicting it on the basis of a series of variables measured at the municipality and AC level. Results do not change substantially with the inclusion or exclusion of this observation.

11. The characteristics of our research design included both an analysis of the dimensionality of input, process and output and of the indirect effects of input on output through process. This made structural equation modelling with a measurement model relying on confirmatory factor analysis (CFA) the method of choice. However, the limited number of observations and lack of clear theoretical expectations regarding the internal composition of the three dimensions ruled out this method. The optimization of CFA models advised against the use of this technique in our situation, mostly due to the low number of observations (70 ACs). The rule of thumb suggests at least 10 cases per variable (we handle 18 indicators, which would make necessary at least 180 observations), but some scholars point out that even more may be needed to estimate more than one factor (Wolf, Harrington, Clark \& Miller, 2013). Because we have three factors, and indirect effects to test (therefore, plenty of parameters to estimate), plus only 70 observations, CFA was definitively not suitable for our purposes. 
12. Among the direct antecedents of this methodological approach, Shields and Young (1993) used path analysis to account for the effects of information asymmetry on participatory budgeting effects, suggesting that further research should include more variables, such as initial goals. Building upon Thomas and Koontz (2011) model, Biddle and Koontz (2014) used a path analysis to link collaborative processes to environmental outcomes through intermediate outputs (e.g. policy goals), finding that specific goals positively impact effects. Newig et al. (2019) claimed to rely on a path analysis to address the relationship between deliberation, capacity building and informed outputs, although their models only handled one dependent variable at a time and they do not test the mediating role of process. Finally, Richards and Charles (2018) relied on experimental data and path analyses to prove that reading intersubjectively relevant information is associated with learning, which in turn assists citizens' sense-making.

13. We do have some socio-demographic information about our respondents: $40 \%$ were women. But we do not know whether these characteristics of respondents are replicated in the internal composition of the AC. For 24 out of 70 cases, the majority of respondents were women.

\section{References}

Agger, A. \& Löfgren, K. (2008). Democratic assessment of collaborative planning processes. Planning Theory 7(2): $145-164$.

Aguiar, F. \& Navarro, C.J. (2000). Democracia y participación ciudadana en los municipios: un mercado político de trastos. Reis 89-111.

Ansell, C. \& Gash, A. (2008). Collaborative governance in theory and practice. Journal of Public Administration Research and Theory 18(4): 543-571.

Baccaro, L., Bächtiger, A. \& Deville, M. (2016). Small differences that matter: The impact of discussion modalities on deliberative outcomes. British Journal of Political Science 46(3): 551.

Baldwin, E. (2020). Why and how does participatory governance affect policy outcomes? Theory and evidence from the electric sector. Journal of Public Administration Research and Theory 30(3): 365-382.

Beierle, T.C. \& Crayford, J. (2002). Democracy in practice. Public participation in environmental decisions. Washington, DC: Resources for the Future.

Bherer, L., Fernández-Martínez, J.L., García Espín, P. \& Jiménez Sánchez, M. (2016). The promise for democratic deepening: The effects of participatory processes in the interaction between civil society and local governments. Journal of Civil Society 12(3): 344-363.

Biddle, J.C. \& Koontz, T.M. (2014). Goal specificity: A proxy measure for improvements in environmental outcomes in collaborative governance. Journal of Environmental Management 145: 268-276.

Burgess, J. \& Chilvers, J. (2006). Upping the ante: A conceptual framework for designing and evaluating participatory technology assessments. Science and Public Policy 33(10): 713-728.

Campos, J.E.L. \& Gonzalez, J.L. (1999). Deliberation councils, government-business-citizen partnerships, and public policy-making: Cases from Singapore, Malaysia, and Canada. Asia Pacific Journal of Management 16(3): 429-448.

Carr, D.S. \& Halvorsen, K. (2001). An evaluation of three democratic, community-based approaches to citizen participation: Surveys, conversations with community groups, and community dinners. Society and Natural Resources 14(2): 107-126.

Coelho, V.S. (2006). Democratization of Brazilian health councils: The paradox of bringing the other side into the tent. International Journal of Urban and Regional Research 30: 656-671.

Cohen, J. (1997). Procedure and substance in deliberative democracy. In J. Bohman \& W. Rehg (eds), Deliberative democracy: Essays on reason and politics. Cambridge, MA: MIT Press.

Cohen, J. \& Rogers, J. (1995). Associations and democracy. New York: Verso.

Cooper, T.L. \& Musso, J.A. (1999). The potential for neighborhood council involvement in American metropolitan governance. International Journal of Organization Theory \& Behavior 2(1/2): 199-232.

Daniell, K.A. (2012). Co-engineering and participatory water management: Organisational challenges for water governance. Cambridge, UK: Cambridge University Press.

Dean, R., Boswell, J. \& Smith, G. (2019). Designing democratic innovations as deliberative systems: The ambitious case of NHS citizen. Political Studies 68(3): 689-709. 
Diamond, L., \& Morlino, L. (eds) (2005). Assessing the quality of democracy. Baltimore, MD: John Hopkins University Press.

Edwards, G. (2008). The 'Lifeworld' as a resource for social movement participation and the consequences of its colonization. Sociology 42(2): 299-316.

Felicetti, A., Niemeyer, S. \& Curato, N. (2016). Improving deliberative participation: Connecting mini-publics to deliberative systems. European Political Science Review 8(3): 427-448.

Fobé, E., Brans, M., Vancoppenolle, D. \& Van Damme, J. (2013). Institutionalized advisory systems: An analysis of member satisfaction of advice production and use across 9 strategic advisory councils in Flanders (Belgium). Policy and Society 32(3): 225-240.

Font, J. (2003). Local participation in Spain: Beyond associative democracy. BCN Political Science Debates (1): $42-64$.

Font, J. \& Galais, C. (2011). The qualities of local participation: The explanatory role of ideology, external support and civil society as organizer. International Journal of Urban and Regional Research 35(5): 932-948.

Font, J., Pasadas del Amo, S. \& Smith, G. (2016). Tracing the impact of proposals from participatory processes: Methodological challenges and substantive lessons. Journal of Public Deliberation 12(1): 3.

Font, J., Smith, G., Galais, C. \& Alarcon, P. (2018). Cherry-picking participation: Explaining the fate of proposals from participatory processes. European Journal of Political Research 57(3): 615-636.

Font, J.; Pasadas, S. \& Fernández-Martínez, J.L. (2019). Participatory motivations in advisory councils: Exploring different reasons to participate. Representation 1-19. https://doi.org/10.1080/00344893.2019.1643774

Fraser, N. (1990). Rethinking the public sphere: A contribution to the critique of actually existing democracy. Social Text (25/26): 56-80. https://doi.org/10.2307/466240

Fung, A. (2003). Deliberative democracy and international labor standards. Governance 16(1): 51-71.

Fung, A. (2006). Varieties of participation in complex governance. Public Administration Review 66: 66-75.

Gastil, J. (2008). Political communication and deliberation. Thousand Oaks, CA: SAGE.

Gastil, J. (2013). A comparison of deliberative designs and policy impact in the EU and across the globe. In R. Kies \& P. Nanz (eds), Is Europe listening to us? Successes and failures of EU citizen consultations. Farnham, UK: Ashgate Publishing.

Gastil, J., Knobloch, K. \& Kelly, M. (2012). Evaluating deliberative public events and projects. Democracy in motion: Evaluating the practice and impact of deliberative civic engagement. Oxford, UK: Oxford University Press.

Gastil, J., Richards, R.C., Ryan, M. \& Smith, G. (2017). Testing assumptions in deliberative democratic design: A preliminary assessment of the efficacy of the participedia data archive as an analytic tool. Journal of Public Deliberation 12(2). https://ssrn.com/abstract=2993451

Goldberg, S., Wyss, D. \& Bächtiger, A. (2020). Deliberating or thinking (twice) about democratic preferences: What German citizens want from democracy. Political Studies 68(2): 311-331.

Grönlund, K., Herne, K. \& Setäla, M. (2017). Empathy in a Citizen Deliberation Experiment. Scandinavian Political Studies 40(4): 457-480.

Hassenforder, E., A. Smajgl \& J. Ward. (2015). Towards understanding participatory processes: Framework, application and results. Journal of Environmental Management 157: 84-95.

Held, D. (1993). Prospects for democracy: North, south, east, west. Stanford, CA: Stanford University Press.

Hernández-Medina, E. (2010). Social inclusion through participation: The case of the participatory budget in São Paulo. International Journal of Urban and Regional Research 34(3): 512-532.

Hoppe, R. (2011). Institutional constraints and practical problems in deliberative and participatory policy making. Policy and Politics 39(2): 163-186.

Innes, J.E. \& Booher, D.E. (1999). Consensus building and complex adaptive systems: A framework for evaluating collaborative planning. Journal of the American Planning Association 65(4): 412.

Jiménez, M. (2001). Sustainable development and the participation of environmental NGOs in Spanish environmental policy. In K. Eder \& M. Kousis (eds), Environmental politics in southern Europe. Dordrecht, The Netherlands: Kluwer Academic.

Karpowitz, C.F. \& Mendelberg, T. (2014). The silent sex: Gender, deliberation, and institutions. Princeton, NJ: Princeton University Press.

Landwehr, C. \& Holzinger, K. (2010). Institutional determinants of deliberative interaction. European Political Science Review 2(3): 373-400. 
Lowndes, V., Pratchett, L. \& Stoker, G. (2001). Trends in public participation: Part 1-local government perspectives. Public Administration 79(1): 205-222.

Morciano, D., Scardigno, A.F., Manuti, A. \& Pastore, S. (2014). An evaluation study of youth participation in youth work: A case study in Southern Italy. Educational Research for Policy and Practice 13(1): 81-100.

Navarro, C. (1999). El sesgo participativo: Innovación democrática en municipios del Sur de Europa (1960-1995). (Vol. 13). Editorial CSIC-CSIC Press.

Newig, J. \& Fritsch, O. (2009). More input - better output: Does citizen involvement improve environmental governance? In I. Blühdorn (ed), In search of legitimacy: Policy making in Europe and the challenge of complexity. (pp. 205-224). Opladen, Germany: B. Budrich.

Newig, J., Challies, E., Jager, N.W., Kochskaemper, E. \& Adzersen, A. (2018). The environmental performance of participatory and collaborative governance: A framework of causal mechanisms. Policy Studies Journal 46(2): 269-297.

Newig, J., Jager, N.W., Kochskämper, E. \& Challies, E. (2019). Learning in participatory environmental governance-its antecedents and effects. Findings from a case survey meta-analysis. Journal of Environmental Policy \& Planning 21(3): 213-227.

Newman, J., M. Barnes, H. Sullivan \& A. Knops (2004). Public participation and collaborative governance. Journal of Social Policy 33: 203-223.

Papadopoulos, Y. \& Warin, P. (2007). Are innovative, participatory and deliberative procedures in policy making democratic and effective? European Journal of Political Research 46(4): 445-472.

Pavitt, C. (1999). Theorizing about the group communication-leadership relationship. In M.S. Poole, D.S. Gouran \& L.R. Frey (eds), The handbook of group communication theory and research. Thousand Oaks, CA: SAGE.

Phillips, A. (1993). Democracy and difference. University Park, PA: Penn State University Press.

Pogrebinschi, T. \& Ryan, M. (2018). Moving beyond input legitimacy: When do democratic innovations affect policy making? European Journal of Political Research 57(1): 135-152.

Richards, J. \& Charles, R. (2018). Making policy information relevant to citizens: A model of deliberative minipublics, applied to the Citizens' Initiative Review. Policy \& Politics 46(3): 445-465.

Romão, d.M.W., Lavalle, A.G. \& Zaremberg, G. (2017). Political intermediation and public policy in Brazil: Councils and conferences in the policy spheres of health and women's rights. In A.G. Lavalle, G. Zaremberg \& V. Guarneros-Meza (eds), Intermediation and representation in Latin America (pp. 31-51). Cham, Switzerland: Palgrave Macmillan.

Rowe, G. \& Frewer, L.J. (2000). Public participation methods: A framework for evaluation. Science, Technology, \& Human Values 25(1): 3-29.

Scharpf, F. (1999). Governing in Europe: Effective and democratic? Oxford, UK: Oxford University Press.

Shields, M.D. \& Young, S.M. (1993). Antecedents and consequences of participative budgeting: Evidence on the effects of asymmetrical information. Journal of Management Accounting Research 5(1): 265-280.

Sintomer, Y. \& De Maillard, J. (2007). The limits to local participation and deliberation in the French 'politique de la ville'. European Journal of Political Research 46(4): 503-529.

Sirianni, C. (2007). Neighborhood planning as collaborative democratic design: The case of Seattle. Journal of the American Planning Association 73(4): 373-387.

Smith, G. (2009). Democratic innovations: Designing institutions for citizen participation. Cambridge, UK: Cambridge University Press.

Smith, G. (2019). Reflections on the theory and practice of democratic innovations. In S. Elstub \& O. Elstub (eds), Handbook of democratic innovation and governance. Cheltenham, UK: Edward Elgar.

Spada, P. \& Ryan, M. (2017). The failure to examine failures in democratic innovation. PS: Political Science \& Politics 50(3): 772-778.

Talpin, J. (2012). Schools of democracy: How ordinary citizens (sometimes) become competent in participatory budgeting institutions. Colchester, UK: ECPR Press.

Thomas, C.W. \& Koontz, T.M. (2011). Research designs for evaluating the impact of community-based management on natural resource conservation. Journal of Natural Resources Policy Research 3(2): 97-111.

Wampler, B. (2007). Can participatory institutions promote pluralism? Mobilizing low-income citizens in Brazil. Studies in Comparative International Development 41(4): 57.

Webler, T. \& Tuler, S. (2002). Unlocking the puzzle of public participation. Bulletin of Science, Technology \& Society 22(3): 179-189. 
Wolf, E.J., Harrington, K.M., Clark, S.L. \& Miller, M.W. (2013). Sample size requirements for structural equation models: An evaluation of power, bias, and solution propriety. Educational and Psychological Measurement 73(6): 913-934.

Young, I.M. (1990). Justice and the politics of difference. Princeton, NJ: Princeton University Press.

Address for correspondence: Carol Galais, Political Science and Public Law department, Universitat Autònoma de Barcelona (UAB), Cerdanyola del Vallès, Edifici B 08193, Bellaterra, Spain. Email: carolgalais@gmail.com 